\title{
Intraoperative Hepatobiliary Injury, CTCAE
}

National Cancer Institute

\section{Source}

National Cancer Institute. Intraoperative Hepatobiliary Injury, CT CAE. NCI Thesaurus.

Code C143605.

A finding of damage to the hepatic parenchyma and/or biliary tract during a surgical procedure. 